\title{
Papers
}

\section{Risk factors for neonatal encephalopathy in Kathmandu, Nepal, a developing country: unmatched case-control study}

\author{
Matthew Ellis, Nilu Manandhar, Dharma S Manandhar, Anthony M de L Costello
}

\begin{abstract}
Objective To determine the risk factors for neonatal encephalopathy among term infants in a developing country.

Design Unmatched case-control study.

Setting Principal maternity hospital of Kathmandu, Nepal.

Subjects All 131 infants with neonatal

encephalopathy from a population of 21609 infants born over an 18 month period, and 635 unmatched infants systematically recruited over 12 months.

Main outcome measures Adjusted odds ratio estimates for antepartum and intrapartum risk factors.

Results The prevalence of neonatal encephalopathy was 6.1 per 1000 live births of which $63 \%$ were infants with moderate or severe encephalopathy. The risk of death from neonatal encephalopathy was $31 \%$. The risk of neonatal encephalopathy increased with increasing maternal age and decreasing maternal height. Antepartum risk factors included primiparity (odds ratio 2.0) and non-attendance for antenatal care (2.1). Multiple births were at greatly increased risk (22). Intrapartum risk factors included non-cephalic presentation (3.4), prolonged rupture of membranes (3.8), and various other complications. Particulate meconium was strongly associated with encephalopathy (18). Induction of labour with oxytocin was associated with encephalopathy in 12 of 41 deliveries (5.7). Overall, 78 affected infants (60\%) compared with 36 controls $(6 \%)$ either had evidence of intrapartum compromise or were born after an intrapartum difficulty likely to result in fetal compromise. A concentration of maternal haemoglobin of less than $8.0 \mathrm{~g} / \mathrm{dl}$ in the puerperium was significantly associated with encephalopathy (2.5) as was a maternal thyroid stimulating hormone concentration greater than $5 \mathrm{mIU} / \mathrm{l}$ (2.1).

Conclusions Intrapartum risk factors remain important for neonatal encephalopathy in developing countries. There is some evidence of a protective effect from antenatal care. The use of oxytocin in low income countries where intrapartum monitoring is suboptimal presents a major risk to the fetus. More work is required to explore the association between maternal deficiency states and neonatal encephalopathy.
\end{abstract}

\section{Introduction}

Neonatal encephalopathy is an abnormal neurobehavioural state, which affects 2-8 per 1000 term infants in the first days of life. ${ }^{1}$ It is importantly associated with early neonatal mortality and long term neurodevelopmental sequelae in countries of both high and low income. ${ }^{2-4}$ The causes of neonatal encephalopathy are heterogeneous, and many start in the antepartum period. ${ }^{5}$ The importance of intrapartum hypoxia remains debatable. ${ }^{6}$ A recent study in Perth, Western Australia, found no evidence of intrapartum hypoxia in over $70 \%$ of cases of moderate or severe neonatal encephalopathy.

The burden of perinatal mortality and morbidity falls disproportionately on low income populations. The World Health Organization estimate that the overall perinatal mortality rate in low income countries in 1995 was 57 per 1000 total births compared with 11 per 1000 in high income countries. ${ }^{8}$ Of the estimated seven million perinatal deaths in 1995 more than four million occurred in Asia and over two million in Africa. In settings where many mothers are stunted, do not access antenatal care, and receive poor obstetric care, it seems likely that intrapartum factors remain important in neonatal encephalopathy.

Antepartum factors related to maternal deficiency states and infection may be of particular importance in low income populations. In Perth, thyroid disease and antepartum haemorrhage were significantly associated with neonatal encephalopathy. ${ }^{5}$ Maternal hypothyroidism secondary to iodine deficiency and maternal anaemia are major public health problems in many areas of the developing world. ${ }^{910}$ Some reports have shown magnesium deficiency in association with neonatal encephalopathy. ${ }^{112}$ Perinatal infection is an important problem in low income countries and is a well recognised cause of neonatal encephalopathy. ${ }^{1314}$ Placental studies show that chorioamnionitis is more likely to be found in mothers with adverse pregnancy outcome..$^{15}$ In Perth, maternal pyrexia and preceding viral illness were both importantly associated with encephalopathy.

We aimed to identify avoidable risk factors for neonatal encephalopathy in a low income setting where large prospective studies of risk factors have not previously been reported, and we chose the main maternity hospital in Kathmandu. We focused on intrapartum factors and maternal deficiency states as the most likely 
practical intervention points. We therefore excluded encephalopathic infants with major birth defects or evidence of congenital or early neonatal infection.

Ethical approval for this study was given by the Nepal Medical Research Council, the ethics committee of the Institute of Child Health, London and the executive committtee of the Maternal and Infant Research Group, Kathmandu. The mothers of all encephalopathic infants were given a full explanation of the diagnosis and offered follow up to monitor neurodevelopmental outcome and to provide appropriate therapeutic intervention.

\section{Subjects and methods}

\section{Setting}

Nepal is a low income country ( $£ 120$ per capita in 1995 ) with a population of 21 million and an infant mortality rate estimated to be 95 per 1000 live births in $1994 .{ }^{16}$ The capital, Kathmandu, is a rapidly growing conurbation situated in a large valley surrounded by hills. The estimated population of the valley is $1100000 .{ }^{17}$ A recent community based study showed that $81 \%$ of mothers living in or near Kathmandu chose to give birth in hospital. ${ }^{18}$

Prasuti Griha is the major maternity hospital in Kathmandu, delivering over 14000 babies annually, around $50 \%$ of all the deliveries in Kathmandu. Poor communications exist with the hilly regions, and a recent audit showed that less than $3 \%$ of women delivering at Prasuti Griha were resident outside the valley. In Nepal there is no functioning referral system for pregnant women. The hospital budget of $£ 350000$ is supplemented by a modest user charge and offers the most competitively priced delivery service in the valley. We therefore consider the mothers delivering at the hospital to be broadly representative of the surrounding population.

Fetal monitoring is by intermittent auscultation; partograms are not used. The caesarean section rate was $10 \%$ during the study period. For labour induction or augmentation, oxytocin infusion is given in dosages of $2 \mathrm{mU}$ per minute titrated up to $15 \mathrm{mU}$ per minute. Amniotomy is not routinely performed. The minimum period of stay for birth is 24 hours. Neonatal resuscitation including suction, oxygen by bag and mask or endotracheal tube, and cardiac massage follows standard procedures and is undertaken by the resident paediatric staff. These are junior doctors serving a training attachment in neonatology. The special care baby unit has 30 cots. There are no facilities for long term ventilation.

\section{Case definition and recruitment}

Neonatal encephalopathy is defined as an abnormal neurobehavioural state commencing within the first 24 hours of life, which consists of an altered conscious level with abnormalities of neuromuscular tone or sucking behaviour. ${ }^{19}$ In addition there may be seizures or abnormalities of respiratory control, primitive reflexes, and brainstem reflexes.

During the 18 month recruitment period a research oriented surveillance system ran throughout the hospital. ${ }^{20}$ All term infants with evidence of neurobehavioural disturbance were examined daily by the junior doctors who had been trained by the princi- pal investigator (ME) using a protocol based on that of Amiel-Tison. ${ }^{21}$ The findings were recorded daily on a standard proforma. Formal operational criteria to grade the severity of encephalopathy in term infants were derived from the syndromic descriptions of Fenichel modified according to more recent studies. ${ }^{19}$ In particular these modifications incorporated the observations that infants with mild neonatal encephalopathy may have signs of not only decreased but increased tone, ${ }^{22}$ that seizure activity may not be clinically detectable and therefore cannot serve as a definitive feature in any grading system, ${ }^{23}$ and that the inclusion of duration in the clinical definition of a grade ${ }^{24}$ renders the scheme contradictory. ${ }^{1}$ Infants with mild (grade 1) encephalopathy were irritable or hyperalert, with either poor suck or an abnormality of tone. Infants with moderate (grade 2) encephalopathy were lethargic, with moderately abnormal tone, poor suck, and depressed Moro and grasp reflexes (seizures were often clinically evident). Infants with severe (grade 3) encephalopathy were comatose, with severely abnormal tone, absent suck, and brainstem malfunction including impaired respiratory drive. Interobserver reliability of the grading system was tested among five paediatric doctors on 27 neurologically abnormal infants. The unweighted kappa measure of interrater agreement was 0.87 , which according to standard interpretations is almost perfect. ${ }^{25} 26$ The final assigned grade corresponded to the worst condition of the infant observed during the period of neurological abnormality.

We included all infants with a gestational age greater than 37 weeks $^{27}$ with evidence of neonatal encephalopathy at 6-24 hours after birth. Exclusion criteria were: preterm infants (less than 37 weeks); severely dysmorphic infants or infants with at least one major congenital abnormality; infants with hepatosplenomegaly, cataracts, and thrombocytopenia indicative of intrauterine infection; infants with microbiological evidence of early neonatal infection, with positive bacteriological culture of blood or cerebrospinal fluid collected within 24 hours of birth; and infants whose neurological condition normalised when hypoglycaemia was corrected.

We excluded 20 of 151 encephalopathic infants recruited; 13 had evidence of infection, two with clinical evidence of intrauterine infection and 11 with early bacterial septicaemia.

\section{Recruitment of controls}

On arrival at the hospital women were issued with an in-patient serial number, given out in chronological order. According to this number every 25th infant born in the hospital was clinically examined, and provided that the infant met the inclusion criteria-with the exception of not being encephalopathic-the infant and mother were recruited as controls. If the infant failed to meet these criteria (usually because of being preterm, occasionally because of congenital abnormalities) we recruited the next infant according to the number system. We followed this procedure for 12 months, generating an unmatched control group of 635 subjects. 


\section{Data collection}

Maternal characteristics and antepartum history were obtained during an interview of the mothers 12-24 hours after delivery, using structured proformas completed by the resident paediatricians. Relevant details of the perinatal history were abstracted systematically from the maternity hospital records at this time. The records form an account of clinical progress and intervention during the intrapartum period and do not include data from the antenatal clinic. All mothers and infants were measured for standard anthropometric variables. Maternal height was measured to the nearest $0.1 \mathrm{~cm}$ with a minimetre (Raven, Dunmow, United Kingdom). Infant weight was measured to the nearest $10 \mathrm{~g}$ with Soehnle (Raven) electronic infant weighing scales. Puerperal blood samples were collected from the mothers by standard venepuncture. The concentration of maternal haemoglobin was estimated at the bedside using the Hemocue photometric method. ${ }^{28}$ Plasma and serum samples were prepared immediately and stored at $-10^{\circ} \mathrm{C}$. All samples were later transferred for assay. Thyroid stimulating hormone assays were performed using an enzyme linked fluorescent assay technique (Vidas bioMérieux, Lyons, France). Assays for free magnesium measured the reflection density of a magnesium-dye complex (Johnson and Johnson, Rochester, NY).

\section{Data analysis}

All data were entered into a computer database, doublechecked, and analysed with Statview (version 4.1) and Stata (version 5.0). The prevalence of neonatal encephalopathy was estimated from routinely collected hospital vital statistics for the denominator data. Confidence intervals for proportions were calculated with the exact binomial distribution.

A core model containing preconceptual and antepartum variables was constructed using those variables found to be significantly associated with neonatal encephalopathy in previous studies. Bivariate associations between neonatal encephalopathy (yes or no) and variables of antepartum exposure were estimated by unconditional logistic regression. We tested potentially confounding variables using a likelihood ratio test procedure (twice the change in the log likelihood), and we included only those additional terms that represented a significant $(\mathrm{P}<0.05)$ component of the model. For the final model we estimated adjusted odds ratios using logistic regression, combining all the significant variables. ${ }^{5}$

For intrapartum and puerperal assay variables of interest, the association with the binary variable neonatal encephalopathy (yes or no) was first estimated using unconditional logistic regression and subsequently adjusted for all the variables in the final antepartum model.

\section{Results}

Between January 1995 and July 1996 there were 21609 live births at Prasuti Griha of which 131 met our case definition for neonatal encephalopathy. The birth prevalence of neonatal encephalopathy was 6.1 per 1000 live births $(95 \%$ confidence interval 5.1 to 7.2). Tables 1 and 2 give the clinical details of the infants. Overall, $120(92 \%)$ of the encephalopathic
Table 1 Early clinical characteristics of infants with neonatal encephalopathy and controls. Values are numbers (percentages) of infants unless stated otherwise

\begin{tabular}{lcc} 
Characteristic & Encephalopathic infants & Controls \\
\hline Apgar score at 1 minute & $\mathrm{n}=131$ & $\mathrm{n}=631$ \\
\hline$\leq 3$ & $120(92)$ & $18(3)$ \\
\hline $4-7$ & $11(8)$ & $503(80)$ \\
\hline$>7$ & $0(0)$ & $110(17)$ \\
\hline Apgar score at 5 minutes & $65(50)$ & $2(<1)$ \\
\hline$\leq 3$ & $66(50)$ & $69(11)$ \\
\hline $4-7$ & $0(0)$ & $560(89)$ \\
\hline$>7$ & $\mathrm{n}=129$ & $\mathrm{n}=612$ \\
\hline Resuscitation & $2(2)$ & $543(89)$ \\
\hline None & $45(35)$ & $65(10)$ \\
\hline Suction, oxygen, or both & $46(36)$ & $2(<1)$ \\
\hline Bag and mask oxygen & $9(7)$ & $1(<1)$ \\
\hline Intubation & $27(21)$ & $1(<1)$ \\
\hline Intubation and cardiopulmonary resuscitation & $\mathrm{n}=130$ & $\mathrm{n}=625$ \\
\hline Birth trauma & $24(18)$ & $4(1)$ \\
\hline Present & $106(82)$ & $621(99)$ \\
\hline Absent & &
\end{tabular}

infants had low (three or less) Apgar scores at one minute and all had low (seven or less) five minute scores. Most of these infants (98\%) required some form of resuscitation compared with $11 \%$ of the controls. Moderate or severe encephalopathy occurred in 63\% of the infants, with seizures in 44\%. Overall, 40 encephalopathic infants died before hospital discharge compared with no controls, giving an estimated early neonatal case fatality of $30.5 \%(22.8 \%$ to $39.2 \%)$. Persisting clinical abnormalities of tone, suck, or conscious level were evident in $56 \%$ of survivors at discharge.

\section{Preconceptual and antepartum risk factors}

Table 3 lists the preconceptual and antepartum risk factors. High maternal age (more than 35 years, odds ratio $4.35,1.04$ to 18.2$)$ and primiparity $(2.0,1.10$ to 3.61) were significant independent risk factors. Maternal education in this population is a proxy for socioeconomic status and did not seem to be a significant independent risk factor. This population sample, however, showed evidence of widespread deprivation (nearly half of the women had never attended school) and this may have diluted any effect. Short stature, defined conventionally in South Asia as a standing

Table 2 Clinical features of 131 infants with neonatal encephalopathy

\begin{tabular}{ll} 
Variable & No (\%) of infants \\
\hline Type of encephalopathy (grade) & \\
\hline Mild (1) & $48(37)$ \\
\hline Moderate (2) & $53(40)$ \\
\hline Severe (3) & $30(23)$ \\
\hline Seizures clinically observed & $74(56)$ \\
\hline No & $57(44)$ \\
\hline Yes & $40(31)$ \\
\hline Yeath before discharge & $91(69)$ \\
\hline No & $40(44)$ \\
\hline Neurological condition at discharge ${ }^{*}$ & $26(29)$ \\
\hline Abrmal & $10(11)$ \\
\hline Abnormal tone & $15(16)$ \\
\hline Abnormal tone, suck, and conscious level
\end{tabular}

*Total of 91 infants. 
Table 3 Preconceptual and antepartum risk factors for neonatal encephalopathy. Values are numbers (percentages) unless stated otherwise

\begin{tabular}{|c|c|c|c|c|}
\hline Risk factor & $\begin{array}{l}\text { Encephalopathic } \\
\text { infants }\end{array}$ & Controls & $\begin{array}{l}\text { Unadjusted } \\
\text { odds ratio }\end{array}$ & $\begin{array}{c}\text { Adjusted odds ratio* } \\
\text { (95\% Cl) }\end{array}$ \\
\hline Maternal age (years) & $n=129$ & $n=633$ & & \\
\hline$<20$ & $22(17)$ & $141(22.3)$ & 1 & 1 \\
\hline $20-24$ & $65(50)$ & $299(47.2)$ & 1.39 & 1.82 (0.95 to 3.51$)$ \\
\hline $25-29$ & $28(22)$ & $136(21.5)$ & 1.31 & 1.87 (0.81 to 4.34$)$ \\
\hline $30-34$ & $10(8)$ & $40(6.3)$ & 1.60 & 2.75 (0.98 to 7.76$)$ \\
\hline$>35$ & $4(3)$ & $17(2.7)$ & 1.51 & 4.35 (1.04 to 18.22$)$ \\
\hline Parity & $n=128$ & $n=634$ & & \\
\hline 0 & $77(60)$ & $364(57.4)$ & 1.12 & 2.0 (1.10 to 3.61 ) \\
\hline$\geqslant 1$ & $51(40)$ & $270(42.6)$ & 1 & 1 \\
\hline Education (years) & $n=109$ & $n=565$ & & \\
\hline None & $60(55)$ & $254(45.0)$ & 1.87 & 1.48 (0.83 to 2.67$)$ \\
\hline $1-5$ & $20(18)$ & $82(14.5)$ & 1.93 & 1.81 (0.88 to 3.73 ) \\
\hline$>5$ & $29(30)$ & $229(40.5)$ & 1 & 1 \\
\hline Height (cm) & $n=131$ & $n=625$ & & \\
\hline$<145$ & $40(31)$ & 79 (12.6) & 4.21 & 3.16 (1.50 to 6.66$)$ \\
\hline $145-154$ & $72(55)$ & $388(62.1)$ & 1.54 & 1.07 (0.57 to 2.01) \\
\hline$\geqslant 155$ & $19(15)$ & $158(25.3)$ & 1 & 1 \\
\hline Previous neonatal death & $n=122$ & $n=634$ & & \\
\hline No & $114(93)$ & $620(97.8)$ & 1 & 1 \\
\hline$\overline{Y e s}$ & $8(7)$ & $14(2.2)$ & 3.10 & 1.89 (0.53 to 6.81$)$ \\
\hline Antenatal care (No of visits) & $\mathrm{n}=126$ & $\mathrm{n}=625$ & & \\
\hline$\geqslant 3$ & $75(60)$ & $444(71.0)$ & 1 & 1 \\
\hline $1-2$ & $16(13)$ & $81(13.0)$ & 1.17 & 0.68 (0.30 to 1.55$)$ \\
\hline None & $35(28)$ & $100(16.0)$ & 2.07 & 2.05 (1.16 to 3.66$)$ \\
\hline Pre-eclampsia & $n=129$ & $\mathrm{n}=632$ & & \\
\hline No & $115(89)$ & $598(94.6)$ & 1 & 1 \\
\hline$\overline{Y e s}$ & $14(11)$ & $34(5.4)$ & 2.14 & 1.86 (0.82 to 4.22$)$ \\
\hline Birthweight (g) & $\mathrm{n}=129$ & $\mathrm{n}=634$ & & \\
\hline$<2500$ & $28(22)$ & $142(22.4)$ & 1.21 & $0.73(0.35$ to 1.51$)$ \\
\hline $2500-2999$ & $66(51)$ & $277(43.7)$ & 1.46 & 1.36 (0.78 to 2.37) \\
\hline$>2999$ & $35(27)$ & $215(33.9)$ & 1 & 1 \\
\hline Infant sex & $n=131$ & $\mathrm{n}=634$ & & \\
\hline Female & $51(39)$ & $298(47.0)$ & 1 & 1 \\
\hline Male & $80(61)$ & $336(53.0)$ & 1.39 & 1.38 (0.84 to 2.26$)$ \\
\hline Twins & $n=131$ & $\mathrm{n}=629$ & & \\
\hline No & $126(96)$ & $627(99.7)$ & 1 & 1 \\
\hline$\overline{Y e s}$ & $5(4)$ & $2(0.3)$ & 12.54 & 22.11 (3.45 to 141.47$)$ \\
\hline
\end{tabular}

${ }^{*}$ Adjusted for effects of all other variables in table.

height of less than $145 \mathrm{~cm}$, was significantly associated with neonatal encephalopathy (3.16, 1.50 to 6.66$).^{29}$ Although over $5 \%$ of the mothers of encephalopathic infants reported previous neonatal death, the numbers were low and were not significant when adjusted for other variables $(1.89,0.53$ to 6.81$)$. A significantly increased risk was found among those mothers who never accessed antenatal care $(2.05,1.16$ to 3.66$)$. A history of pre-eclampsia was associated with a non-significant increased risk (1.86, 0.82 to 4.22$)$. Over $20 \%$ of both encephalopathic infants and controls were of low birth weight (less than $2500 \mathrm{~g}$ ) and no study infants had a birth weight of more than $4000 \mathrm{~g}$. No association between encephalopathy and birth weight was found in this population. An excess of boys was observed among encephalopathic infants but this was not independently significant $(1.38,0.84$ to 2.26$)$. Plurality (twins in all cases) carried a highly significant increased risk despite the small numbers in this study (22.11, 3.45 to 141.47). Of the five cotwins of encephalopathic infants, two were neurologically normal, one was anencephalic, one was a macerated stillbirth, and no data were available for one. Of the exposures of a priori interest a history of pre-eclampsia and sex of the infant did not contribute significantly to the model
( $\mathrm{P}$ values on likelihood ratio testing of 0.066 and 0.215 respectively). These variables have been retained for comparative purposes. Potentially confounding variables that did not contribute significantly to the model were month of birth and a history of maternal anaemia.

\section{Intrapartum risk factors}

Table 4 lists the intrapartum risk factors. Around 5\% of term infants had a non-cephalic presentation among whom there was a significant excess risk of encephalopathy $(3.35,1.38$ to 8.11$)$. A significant risk was associated with prolonged rupture of membranes (3.84, 1.56 to 9.47$)$. Forty one of 766 deliveries $(5 \%)$ were induced with oxytocin, of which $12(29 \%)$ resulted in encephalopathic infants $(5.28,2.03$ to 13.76). No encephalopathic infants were delivered by elective caesarean section. Instrumental delivery was associated with greater risk to the infant than emergency caesarean section. Serious intrapartum complications were more common among encephalopathic infants (28; $21 \%)$ than controls (17; 3\%). In encephalopathic infants these included obstructed labour resulting in a prolonged second stage, instrumental or operative delivery (19 infants), cord prolapse (four), maternal eclampsia (two), intrapartum haemorrhage (two), and uterine rupture (one). Meconium stained liquor and especially thick (particulate) meconium was importantly associated with encephalopathy (18.21, 8.05 to 41.18). When oxytocin administration was coded according to augmentation or induction, induction was more significantly associated with adverse neonatal outcome $(9.09,3.32$ to 24.83$)$ even after adjustment for antenatal confounders including a history of preeclampsia. Among the control population induced labour was likely to be more protracted (mean 19 hours) than spontaneous labour (14). Although fetal monitoring was recorded more frequently during induced labours (mean 10 times) than during spontaneous labours (mean three times), there was no systematic monitoring of uterine contractions. Despite the liberal use of oxytocin for augmentation, prolonged labour as conventionally defined was common but not significantly associated with encephalopathy $(1.04,0.60$ to 1.80$)$. Nor did there seem to be an important association with time from admission to delivery. No association was found with day of delivery, a proxy for the obstetric team providing care.

Like the Perth group, ${ }^{7}$ we used the following criteria to estimate the proportion of infants who had been exposed to possible intrapartum hypoxia: the presence of an abnormal fetal heart rate on auscultation (less than 120 beats per minute or more than 160) or thick meconium in labour, or both, together with a one minute Apgar score of less than three and a five minute Apgar score of less than seven. Overall, 56 (43\%) encephalopathic infants and 19 (3\%) controls fulfilled these criteria. A further 22 encephalopathic infants $(17 \%)$ did not meet these criteria but had evidence of a significant intrapartum event; clinical evidence of obstructed labour resulting in either a prolonged second stage or instrumental or operative delivery (18 infants), cord prolapse (3), and major intrapartum haemaorrhage (1). Overall, 78 encephalopathic infants $(60 \%)$ compared with 36 controls $(6 \%)$ either had evidence of intrapartum compromise or were born 
after an intrapartum difficulty likely to result in fetal compromise.

\section{Puerperal maternal assays}

Routine antenatal blood assay is not performed in low income settings. Given the large baseline population for this study, antenatal blood sampling was not feasible. We therefore had to rely upon maternal blood assays performed in the puerperium. Table 5 presents the assay data for haemoglobin, thyroid stimulating hormone, and magnesium. Given the differing cut off points used in the definition of maternal anaemia, haemoglobin concentration was stratified in $2 \mathrm{~g} / \mathrm{dl}$ bands. Low haemoglobin concentrations (less than 8 $\mathrm{g} / \mathrm{dl}$ ) were significantly associated with encephalopathy (odds ratio 2.64, 1.00 to 7.01). Overall, $16 \%$ of control mothers had increased concentrations of thyroid stimulating hormone (greater than $5 \mathrm{mIU} / \mathrm{l}$ ) suggestive of thyroid hormone deficiency. This proportion increased to $24 \%$ in mothers of encephalopathic infants, with a significantly increased risk of encephalopathy after adjustment for antepartum variables (2.14, 1.19 to 3.82). Almost half of the control mothers had magnesium concentrations below a conventional cut off point. This was not associated with a significantly increased risk of encephalopathy in their offspring.

\section{Discussion}

\section{Neonatal encephalopathy}

In the low income setting of Kathmandu, as in the high income setting of Perth, increasing maternal age and multiple birth are associated with an increased risk of neonatal encephalopathy. Unlike Perth, in the less well nourished Kathmandu population both short maternal stature and primiparity are significantly associated with encephalopathy. Indirect data suggested an association with maternal hypothyroidism and severe anaemia. Almost 1 in 5 of this urban population had never received antenatal care and their infants were at significantly greater risk of encephalopathy than those who had attended for antenatal care. In contrast to Perth, there was no apparent association with maternal socioeconomic status, low infant birth weight, or sex of the infant.

Intrapartum monitoring detected evidence of intrapartum hypoxia affecting $43 \%$ of the encephalopathic infants. As in Perth there was a particularly strong association with particulate meconium. Infants
Table 4 Intrapartum risk factors for neonatal encephalopathy. Values are numbers (percentages) unless stated otherwise

\begin{tabular}{|c|c|c|c|c|}
\hline Risk factor & $\begin{array}{l}\text { Encephalopathic } \\
\text { infants }\end{array}$ & Controls & $\begin{array}{l}\text { Unadjusted } \\
\text { odds ratio }\end{array}$ & $\begin{array}{l}\text { Adjusted odds ratio* } \\
(95 \% \mathrm{Cl})\end{array}$ \\
\hline Presentation & $n=131$ & $\mathrm{n}=635$ & & \\
\hline Cephalic & $119(91)$ & $611(96.2)$ & 1 & 1 \\
\hline Non-cephalic & $12(9)$ & $24(3.8)$ & 2.57 & 3.35 (1.38 to 8.11$)$ \\
\hline $\begin{array}{l}\text { Prolonged rupture of } \\
\text { membranes ( }>24 \text { hours) }\end{array}$ & $\mathrm{n}=122$ & $\mathrm{n}=624$ & & \\
\hline No & $109(89)$ & $597(95.7)$ & 1 & 1 \\
\hline Yes & $13(11)$ & $27(4.3)$ & 2.64 & 3.84 (1.56 to 9.47$)$ \\
\hline Onset of labour & $n=130$ & $n=620$ & & \\
\hline Spontaneous & $118(91)$ & $591(95.3)$ & 1 & 1 \\
\hline Induced & $12(9)$ & $29(4.7)$ & 2.07 & 5.28 (2.03 to 13.76$)$ \\
\hline Mode of delivery & $n=130$ & $\mathrm{n}=631$ & & \\
\hline Elective caesarean section & $0(0)$ & $16(2.5)$ & $\dagger$ & $\dagger$ \\
\hline Unassisted vaginal & $85(65)$ & $553(87.6)$ & 1 & 1 \\
\hline Vacuum & $17(13)$ & $16(2.5)$ & 6.91 & 7.93 (3.02 to 20.78 ) \\
\hline Forceps & $5(4)$ & $4(0.6)$ & 8.13 & 6.11 (1.005 to 37.17$)$ \\
\hline Emergency caesarean section & $23(18)$ & $42(6.7)$ & 3.56 & 3.91 (1.96 to 7.84$)$ \\
\hline Intrapartum complications & $n=131$ & $\mathrm{n}=634$ & & \\
\hline None & $103(79)$ & $617(97.3)$ & 1 & 1 \\
\hline Clinically obstructed labour & $19(15)$ & $16(2.5)$ & 7.11 & 5.73 (2.30 to 14.23$)$ \\
\hline Other & $9(7) \ddagger$ & $1(0.2) \S$ & 53.9 & 28.16 (2.88 to 275.6$)$ \\
\hline Meconium & $\mathrm{n}=127$ & $\mathrm{n}=607$ & & \\
\hline None & $66(52)$ & $573(94.4)$ & 1 & 1 \\
\hline Thin & $20(16)$ & $21(3.5)$ & 8.27 & 6.04 (2.56 to 14.25$)$ \\
\hline Thick & $41(32)$ & $13(2.1)$ & 27.38 & 18.21 (8.05 to 41.18$)$ \\
\hline Syntocinon & $\mathrm{n}=130$ & $\mathrm{n}=620$ & & \\
\hline None & $68(52)$ & $452(72.9)$ & 1 & 1 \\
\hline Induction & $12(9)$ & $29(4.7)$ & 2.75 & 9.09 (3.32 to 24.83) \\
\hline Augmentation & $50(39)$ & $139(22.4)$ & 2.39 & 3.51 (2.04 to 6.07$)$ \\
\hline Duration of labour (hours) & $n=123$ & $\mathrm{n}=598$ & & \\
\hline $\begin{array}{l}<24 \text { primiparous or }<12 \\
\text { multiparous }\end{array}$ & $87(71)$ & $429(71.7)$ & 1 & 1 \\
\hline $\begin{array}{l}>24 \text { primiparous or }>12 \\
\text { multiparous }\end{array}$ & $36(29)$ & $169(28.3)$ & 1.05 & $1.04(0.60$ to 1.80$)$ \\
\hline Admission to delivery (hours) & $n=130$ & $\mathrm{n}=622$ & & \\
\hline$<1$ & $19(15)$ & $99(15.9)$ & 1 & 1 \\
\hline $1-4$ & $34(26)$ & $153(24.6)$ & 1.15 & 1.23 (0.57 to 2.65$)$ \\
\hline $5-12$ & $40(31)$ & $208(33.4)$ & 1.00 & $1.23(0.57$ to 2.64$)$ \\
\hline $12-24$ & $22(17)$ & $91(14.6)$ & 1.25 & $1.96(0.85$ to 4.50$)$ \\
\hline$>24$ & $15(12)$ & $71(11.4)$ & 1.10 & $1.58(0.60$ to 4.14$)$ \\
\hline
\end{tabular}

*Adjusted for maternal age, parity, education, height, previous neonatal death, antenatal care, pre-eclampsia, birth weight, sex of infant, and plurality.

†Omitted from odds ratio estimation owing to zero prevalence in cases.

$\ddagger$ Cord prolapse (four), maternal convulsion (two), haemorrhage (two), uterine rupture (one). $\S$ Maternal convulsion (one).

presenting in a non-cephalic position were at significantly greater risk. Intrapartum complications were importantly associated with encephalopathy. In Kathmandu $60 \%$ of encephalopathic infants had evidence of possible intrapartum hypoxia compared

Table 5 Effects of anaemia, hypothyroidism, and hypomagnesaemia on risk of neonatal encephalopathy. Values are numbers (percentages) of infants unless stated otherwise

\begin{tabular}{|c|c|c|c|c|}
\hline Maternal risk factor & Encephalopathic infants & Controls & Unadjusted odds ratio & Adjusted odds ratio* $(95 \% \mathrm{CI})$ \\
\hline Haemoglobin (g/dl) & $\mathrm{n}=128$ & $\mathrm{n}=614$ & & \\
\hline$\geqslant 12.0$ & $44(34)$ & $285(46.4)$ & 1 & 1 \\
\hline $10.0-11.99$ & $47(37)$ & $201(32.7)$ & 1.51 & 1.58 (0.91 to 2.77$)$ \\
\hline $8.0-9.99$ & $26(20)$ & $99(16.1)$ & 1.70 & $1.45(0.73$ to 2.90$)$ \\
\hline$<8.0$ & $11(9)$ & $29(4.7)$ & 2.45 & 2.64 (1.00 to 7.01$)$ \\
\hline Thyroid stimulating hormone (mIU/l) & $n=131$ & $\mathrm{n}=635$ & & \\
\hline$>5$ & $31(24)$ & $100(15.8)$ & 1.66 & 2.14 (1.19 to 3.82$)$ \\
\hline$<5$ & $100(76)$ & $535(84.2)$ & 1 & 1 \\
\hline Magnesium (mmol/l) & $\mathrm{n}=122$ & $n=631$ & & \\
\hline$<0.75$ & $74(61)$ & $288(45.6)$ & 1.29 & $1.37(0.83$ to 2.25$)$ \\
\hline$>0.75$ & $48(39)$ & $343(54.4)$ & 1 & 1 \\
\hline
\end{tabular}

*Adjusted for maternal age, parity, education, height, previous neonatal death, antenatal care, pre-eclampsia, birth weight, sex of infant, and plurality. 
with 29\% in Perth. The adjusted odds ratios for intrapartum management were higher in Kathmandu than in Perth for all modes of delivery intervention but, as in Perth, emergency caesarean section seemed to be associated with a lower risk of encephalopathy than instrumental vaginal deliveries. Twelve encephalopathic infants $(9 \%)$ were born after induction with oxytocin.

\section{Study limitations}

There is, as yet, no widely agreed definition for neonatal encephalopathy. ${ }^{30}$ We chose to define neonatal encephalopathy so as to enable comparison with prevalence studies of hypoxic-ischaemic encephalopathy in other settings. ${ }^{4}$ We have shown elsewhere that grade 1 (mild) encephalopathy is associated with significant neonatal mortality in Kathmandu unlike in high income settings. ${ }^{3}$ We therefore report this risk factor study for all grades of encephalopathy combined. Our surveillance system was designed to detect all term infants with early neonatal encephalopathy. It is possible that a small number of mildly encephalopathic infants escaped our attention, but moderate and severe encephalopathy is not a subtle syndrome and presents within 24 hours of birth. ${ }^{19}$ Unlike the Perth group we did not have the benefit of detailed maternity records combining antenatal findings with continuously monitored intrapartum data. Our antepartum data relied on retrospective maternal interview, which may have been open to recall bias. Neither the interviewers nor the participants were familiar with the precise study aims and had no explicit gain from biased replies, and no women refused interview. The intrapartum data were taken from contemporaneous clinical notes and are therefore of higher reliability within the constraints of this low income setting. Logistics dictated a reduced period of 12 months for recruitment of controls-the same recruitment period as for the cases would have been preferable. The limitations of locally available microbiological facilities may have had some effect on our detection rate for early neonatal infection. Assays performed in the puerperium are only indirect measures of prior status during pregnancy. These assay data may also be confounded by several variables including type of delivery and interval beween birth and venepuncture.

\section{Implications for perinatal care in low income settings}

We have previously shown that neonatal encephalopathy in low income settings carries a high risk of death in infancy, with 441 deaths per 1000 live births by one year of age (95\% confidence interval 343 to 543) compared with 37 deaths per 1000 live births among term newborn infants not requiring special care (10 to 94). Most encephalopathic infants who died (89\%) did so in the early neonatal period. Of the 27 survivors of moderate encephalopathy, 16 developed major neurodevelopmental impairment (59\%, 39\% to 78\%). Neonatal encephalopathy continues to importantly contribute to neonatal mortality and long term morbidity in this population.

Absent antenatal care was associated with an increased risk of encephalopathy in our study. The safe motherhood policy of Nepal's government recommends a minimum of three antenatal visits during pregnancy, focusing on risk screening, immunisation against tetanus, anaemia prophylaxis and treatment, and health and nutrition education. The apparent protective effect of antenatal care in Kathmandu needs to be interpreted with care. It is likely that both exposure and outcome are confounded by socioeconomic factors. The only proxy for socioeconomic status we were able to measure was maternal educational status. The effect remains after adjustment for this. It is biologically plausible that risk screening (when combined with appropriate advice and management) and anaemia prophylaxis may be protective to the fetus.

Particulate meconium was strongly associated with encephalopathy in Kathmandu as elsewhere. ${ }^{31-34}$ This lends indirect support to the developing case for the routine use of intrapartum amnioinfusion-the infusion of normal saline through the patent cervix when labour is complicated by the passage of fresh meconium in utero. A recent study from Zimbabwe found a protective effect of amnioinfusion in hypoxicischaemic encephalopathy (odds ratio $0.07,0.01$ to 0.56 ), with no evidence of increased risk of puerperal pyrexia. ${ }^{35}$ Although there remains uncertainty about the potential effect of amniofusion on vertical transmission of HIV, a recent systematic review recommended its use where peripartum surveillance is limited, as in many low income settings. ${ }^{36}$

The most potentially preventable risk factor for encephalopathy was induction of delivery with oxytocin. Overall, 12 encephalopathic infants (9\%) compared with 29 controls $(5 \%)$ were induced. The calculated population attributable fraction of encephalopathy (the proportion that may be reversible) after induced delivery in this population is $5 \%$. This assumes a causal relation. Common indications for induction in Kathmandu are postmaturity and pre-eclampsia. That induction in Kathmandu remains a significant independent risk factor for encephalopathy after adjustment for other significant exposures argues for an independent causal effect. Hypertonic uterine contraction, a dose dependent side effect of oxytocin, reduces placental perfusion and hence oxygen supply to the fetus. It is therefore plausible that the association between induction and adverse pregnancy outcome is in part causal.

The Perth group have previously reported an odds ratio of 2.3 (1.2 to 4.6) on univariate analysis for encephalopathy associated with induction. ${ }^{37}$ On multivariate analysis of a larger cohort, however, they found the adjusted odds ratio to be non-significant $(0.97,0.57$ to 1.68). Similarly no association between induction and early neonatal seizures was found during the Cardiff births' survey (1.1, 0.5 to 2.1$){ }^{38}$

In the late 1980s in Canada a study of elective induction for postmaturity in comparison with conservative management utilising serial antenatal monitoring found no difference in perinatal mortality or neonatal morbidity between the two groups. ${ }^{39} \mathrm{~A}$ retrospective study of induced deliveries in a UK population at low risk at term found no difference in neonatal morbidity but an increased proportion of operative and instrumental deliveries in the induced group. ${ }^{40}$

The Jamaican perinatal mortality survey by contrast described a significant association (odds ratio 2.3) between induction and intrapartum death. ${ }^{41} \mathrm{~A}$ 


\section{What is already known on this topic}

The burden of perinatal mortality and morbidity falls disproportionately on low income populations such as those of Kathmandu in Nepal, and antepartum factors related to maternal deficiency states and infection may be of particular importance in such populations

\section{What this study adds}

Independent preconceptual and antenatal risk factors for neonatal encephalopathy in Kathmandu include short maternal stature, high maternal age, primiparity, lack of antenatal care, and multiple birth

Independent intrapartum risk factors include non-cephalic presentation, prolonged rupture of membranes and the intrapartum complications of obstructed labour, cord prolapse, and uterine rupture; there was evidence of intrapartum hypoxia in $60 \%$ of encephalopathic infants

The use of oxytocin in low income countries where intrapartum monitoring is suboptimal presents a significant risk to the fetus, however, neonatal encephalopathy was not limited to those augmented with oxytocin but was also seen when labour was induced by oxytocin

Newborn encephalopathy was associated with indicators of maternal hypothyroidism and severe anaemia

recent study from Jerusalem assessed the rate of intrapartum complications for three different methods of induction among 210 women at high risk in a teaching hospital setting. Compared with the amniotomy group, the oxytocin group showed an increased rate of intrapartum complications (adjusted odds ratio 5.1, 1.5 to 17.5). This difference was not seen when the prostaglandin group was compared with the amniotomy group $(0.7,0.3$ to 1.6$)$.

Elective induction of labour, although commonly practised in high income countries, remains poorly studied and generally discouraged. ${ }^{42}$ Even in high income countries labour induction is performed more often in the least capable facilities with no consistent management protocols. ${ }^{43} \mathrm{~A}$ recent review suggests that induction of labour should only be countenanced "when personnel are comfortable with the emergency measures to treat uterine hypertonus and resulting fetal compromise because medical induction of labor carries with it more potential for uterine hyperstimulation than spontaneous labor." ${ }^{44}$ We hypothesise that labour induction is safe when obstetric care is optimal but poses a significant added risk to the fetus when fetal monitoring is suboptimal and uterine monitoring is non-existent, as in Kathmandu.

\section{Conclusion}

Both antepartum and intrapartum factors are important in the causation of neonatal encephalopathy in developing countries. In the short term there are likely to be continuing gains from improvements to intrapartum care. Research and development priorities are audit of outcome after oxytocin induction and further investigation of the use of amnioinfusion. Improvements in the public health of women with associated gains in female growth and nutrition must remain a longer term goal.

This work was only possible with the support of the Maternal and Infant Research Activities (MIRA) team and colleagues at Prasuti Griha, Kathmandu. Juana Willumson arranged transfer of the biological samples to the Institute of Neurology, London where Dr John Land and his team performed the assays. Dr Liz Paul and Dr Linda Hunt gave obstetrical advice.

Contributors: AMdeLC originated the idea for the study, assisted with development of the study protocol, supervised fieldwork, assisted with data analysis, and criticised drafts of the paper. DSM assisted with the study design, supervised fieldwork, and criticised drafts of the paper. NM conducted neurological screening, supervised data collection, and assisted with data entry. ME developed the study protocol, supervised all aspects of data collection, led the data analysis, and wrote the paper; he will act as guarantor for the paper.

Funding: This project was funded by the Wellcome Trust. The Maternal and Infant Research Activities group has also received support from the Department for International Development.

Competing interests: None declared.

1 Leviton A, Nelson KB. Problems with definitions and classifications of newborn encephalopathy. Pediatr Neurol 1992;8:85-90.

2 Levene MI. Management and outcome of birth asphyxia. In: Levene MI, Lilford RJ, Bennett MJ, Punt J, eds. Fetal and neonatal neurology and neurosurgery. London: Churchill Livingstone, 1995:427-42.

3 Ellis M, Manandhar DS, Manandhar N, Shrestha P, Shrestha L, Costello AM de L. One year outcome of neonatal encephalopathy in Kathmandu, Nepal. Dev Med Child Neurol 1999;41:689-95.

4 Ellis M, Manandhar DS, Manandhar N, Wyatt JS, Bolam AJ, Costello AM de L. Stillbirths and neonatal encephalopathy in Kathmandu, Nepal: an estimate of the contribution of birth asphyxia to perinatal mortality in a low income urban population. Paediatr Perinat Epidemiol 2000;14:39-52.

5 Badawi N, Kurinczuk JJ, Keogh JM, Alessandri LM, O'Sullivan F, Burton PR, et al. Antepartum risk factors for newborn encephalopathy: the Western Australian case-control study. BMJ 1998;317:1549-53.

6 Edwards AD, Nelson KB. Neonatal encephalopathies. BMJ 1998;317: $1537-8$

7 Badawi N, Kurinczuk JJ, Keogh JM, Alessandri LM, O'Sullivan F, Burton PR, et al. Intrapartum risk factors for newborn encephalopathy: the Western Australian case-control study. BMJ 1998;317:1554-8.

8 World Health Organization. Perinatal mortality: a listing of available information. WHO/FRH/MSM/96.7. Geneva: WHO, 1996.

9 Mahomed K, Gulmezoglu AM. Maternal iodine supplements in areas of deficiency. In: Cochrane Collaboration. Cochrane Library. Issue 3. Oxford: Update Software, 1998.

10 Mahomed K. Routine iron supplementation during pregnancy. In: Neilson JP, Crowther CA, Hodnett ED, Hofmeyr GJ, Keirse MJNC, eds. Pregnancy and childbirth module of the Cochrane database of systematic reviews. Cochrane Collaboration. Cochrane Library. Issue 3. Oxford: Update Software, 1997.

11 Ilves P, Blennow M, Kutt E, Magi ML, Kudrjavtseva G, Lagercrantz H, et al. Concentrations of magnesium and ionized calcium in umbilical cord blood in distressed term newborn infants with hypoxic ischaemic encephalopathy. Acta Paediatr 1996;85:1348-50.

12 Harrison V, Peat G. Red blood cell magnesium and hypoxic-ischaemic encephalopathy. Early Hum Dev 1997;47:287-96.

13 Bhutta ZA. Effective interventions to reduce neonatal mortality and morbidity from perinatal infection. In: Costello AM de L, Manandhar DS, eds. Improving newborn infant health in developing countries. London: Imperial College Press, 2000:289-308.

14 Low JA, Galbraith RS, Muir DW, Killen HL, Pater EA, Karchmar EJ. The relationship between perinatal hypoxia and newborn encephalopathy. Am J Obstet Gynecol 1985;152:256-60.

15 Redline RW. Placental pathology: a neglected link between basic disease mechanisms and untoward pregnancy outcome. Curr Opin Obstet Gynecol $1995 ; 7: 10-5$

16 World Bank. World development report. Oxford: Oxford University Press, 1996

17 Central Bureau of Statistics. The analysis of the 1991 population census. Kathmandu: His Majesty's Government Nepal, 1993.

18 Bolam AJ, Manandhar DS, Shrestha P, Manandhar B, Ellis M, Costello AM de L. Maternity care utilisation in the Kathmandu valley: a community based study. J Nepal Med Assoc 1997;35:122-9.

19 Fenichel JM. Hypoxic-ischaemic encephalopathy in the newborn. Arch Neurol 1983;40:261-6.

20 Ellis ME. The public health importance of birth asphyxia in Kathmandu, Nepal. $\mathrm{PhD}$ thesis. London: University College London, 1999.

21 Amiel-Tison C. Clinical assessment of the infant nervous system. In: Levene MI, Lilford RJ, Bennett MJ, Punt J, eds. Fetal and neonatal neurology and neurosurgery. Edinburgh: Churchill Livingstone, 1995:83-104. 
22 Amiel-Tison C, Ellison P. Birth asphyxia in the fullterm newborn: early assessment and outcome. Dev Med Child Neurol 1986;28:671-82

23 Connel J, Oozer R, DeVries L, Dubowitz LMS, Dubowitz V. Continuous EEG monitoring of neonatal seizures: diagnostic and prognostic considerations. Arch Dis Child 1989;64:452-8.

24 Levene MI, Kornberg J, Williams THC. The incidence and severity of post-asphyxial encephalopathy in full term infants. Early Hum Dev 1985;11:21-6.

25 Landis JR, Koch GG. The measurement of observer agreement for categorical data. Biometrics 1977;33:159-74.

26 Ellis M, Manandhar N, Manandhar DS, Costello AM de L. An Apgar score of three or less at one minute is not diagnostic of birth asphyxia but is a useful screening test for neonatal encephalopathy. Indian Pediatr 1988:35:415-21.

27 Parkin JM, Hey EN, Clowes JS. Rapid assessment of gestational age at birth. Arch Dis Child 1976;51:259-63.

28 Makarem A. Principles and technics. In: Henry RJ, Cannon DC, Winkelman JW, eds. Clinical chemistry. Hagerstown, MD: Harper and Row, 1974:1125-47.

29 Reddy V, Shekar M, Rao P, Gillespie S. Nutrition in India. Hyderabad: National Institute of Nutrition, 1992.

30 Badawi N, Kurinczuk JJ, Stanley FJ, Keogh JM, Burton PR. Intrapartum risk factors are important in developing world. [Letter.] BMJ 1999:318:1415

31 Wiswell TE, Bent RC. Meconium staining and the meconium aspiration syndrome. Pediatr Clin North Am 1993;40:955-81.

32 Dijxhoorn MJ, Visser GHA, Fidler VJ, Touwen BCL, Huisjes HJ. Apgar score, meconium and acidaemia at birth in relation to neonatal neurological morbidity in term infants. Br J Obstet Gynaecol 1986;93:217-22.

33 Gaffney G, Sellers S, Flavell V, Squier M, Johnson A. Case-control study of intrapartum care, cerebral palsy, and perinatal death. BMJ 1994;308: $743-50$.
34 Daga AS, Daga SR, Patole SK. Risk assessment in birth asphyxia. J Trop Pediatr 1990;36:34-9.

35 Mahomed K, Mulambo T, Woelk G, Hofmeyr GJ, Gulmezoglu AM. The collaborative randomised amnioinfusion for meconium project (CRAMP): 2. Zimbabwe. Br J Obstet Gynaecol 1998;105:309-13.

36 Hofmeyer GJ. Amnioinfusion for meconium-stained liquor in labour. In Cochrane Library. Issue 1. Oxford: Update Software, 2000.

37 Adamson SJ, Alessandri LM, Badawi N, Burton PR, Pemberton PJ, Stanley F. Predictors of neonatal encephalopathy in full term infants. $B M J$ 1995;311:598-602.

38 Minchom P, Niswander K, Chalmers I, Dauncey M, Newcombe R, Elbourne D, et al. Antecedents and outcome of very early neonatal seizures in infants born at or after term. Br J Obstet Gynaecol 1987;94:431-9.

39 Hannah ME, Hannah WJ, Hellman J, Hewson S, Milner R, Willan A. Induction of labor as compared with serial antenatal monitoring in postterm pregnancy. N Engl J Med 1992;326:1587-92.

40 Yudkin P, Frumar AM, Anderson ABM. A retrospective study of induction of labour. Br J Obstet Gynaecol 1979;86:257-65.

41 Escoffery C, Greenwood R, Ashley D, Coard K, Keeling J, Golding J Deaths associated with intrapartum asphyxia in Jamaica. Paed Perinat Epi dem 1994;8(suppl 1):119-42.

42 Jackson M, Regan C. Elective induction of labor. Clin Obstet Gynecol 1997;40:496-509.

43 Jarvelin MR, Hartikainen-Sorri AL, Rantakallio P. Labour induction policy in hospitals of different levels of specialisation. BrJ Obstet Gynaecol 1993;100:310-5.

44 Laube DW. Induction of labor. Clin Obstet Gynecol 1997;40:485-95.

(Accepted 21 January 2000)

\title{
Prospective cohort study to determine if trial efficacy of anticoagulation for stroke prevention in atrial fibrillation translates into clinical effectiveness
}

\author{
Lalit Kalra, Gloria Yu, Inigo Perez, Anil Lakhani, Nora Donaldson
}

Editorial

by Connolly

Department of

Medicine, Guy's,

King's, and

St Thomas's School

of Medicine,

London SE5 9PJ

Lalit Kalra

professor of stroke

medicine

Inigo Perez

research fellow

Department of

Medicine for the

Elderly, Bromley

Hospitals NHS

Trust, Orpington

Hospital, Kent

BR6 9JU

Gloria Yu

consultant physician

Department of

Haematology,

Bromley Hospitals

NHS Trust,

Farnborough

Hospital,

Orpington, Kent

BR6 8ND

Anil Lakhani

consultant

haematologist

continued over

BMJ 2000;320:1236-9

\begin{abstract}
Objective To determine whether trial efficacy of prophylaxis with warfarin for patients with atrial fibrillation at high risk of stroke translates into effectiveness in clinical practice.

Design Two year prospective cohort study. Setting District general hospital.
\end{abstract}

Participants 167 patients with atrial fibrillation and at high stroke risk who were eligible for anticoagulation. Interventions Long term anticoagulation with warfarin at adjusted doses to maintain an international normalised ratio of 2.0-3.0.

Main outcome measures Comparison of patient characteristics, comorbidity, anticoagulation control, stroke rate, and haemorrhagic complications with pooled data from five randomised controlled trials. Results Patients in the study group were seven years older (95\% confidence interval 4 to 10$)$ and comprised 33\% more women than patients in the pooled trials. The international normalised ratio was in the target range for $61 \%$ of the time (range $37 \%-85 \%$ ), below for $26 \%$ of the time (range $8 \%-32 \%$ ), and above for $13 \%$ of the time (range $6 \%-26 \%$ ). The time that patients in the study group spent in the target range was significantly less than in the pooled analysis. The incidence of stroke in the study group $(2.0 \%$ per year, $0.7 \%$ to $4.4 \%)$ was comparable to that of patients receiving warfarin in pooled studies $(1.4 \%$, $0.8 \%$ to $2.3 \%)$. Per year the incidence of major $(1.7 \% v$
$1.6 \%)$ and minor $(5.4 \%$ v $9.2 \%)$ bleeding complications was also similar.

Conclusion Rates of stroke and major haemorrhage after anticoagulation in clinical practice were comparable to those obtained from pooled data from randomised controlled studies for patients with atrial fibrillation at high risk of stroke.

\section{Introduction}

Many randomised controlled studies have shown the effectiveness of anticoagulation in preventing stroke in patients with atrial fibrillation. ${ }^{1-7}$ Furthermore, clinical guidelines have been developed to identify patients at high risk who will benefit most from this intervention. $^{8-11}$ Recent studies have, however, shown that anticoagulation is underused in clinical practice. ${ }^{12-16}$

Several reasons have been given for the low rate of anticoagulation in eligible patients with atrial fibrillation. Major randomised trials were considered unrepresentative of clinical practice because only a small percentage of screened patients were included, and the proportion of men and younger patients was higher than expected in community settings. ${ }^{15}$ A reanalysis of pooled data showed that the benefits of anticoagulation may have been overestimated, ${ }^{17}$ and there seemed to be little absolute reduction in stroke rates with anticoagulation in patients with atrial fibrillation unselected for stroke risk. ${ }^{18}$ Additionally, a retrospective review of case notes concluded that the extent of anti- 